\title{
Activity of liver microsomal enzymes during the chronic phase of murine schistosomiasis
}

F.P. Conte, A.A. Fidalgo-Neto, D.A. Manhães-Rocha, F.J.R. Paumgartten and A.C.A.X. De-Oliveira

\author{
Laboratório de Toxicologia Ambiental, Departamento de Ciências Biológicas, \\ Escola Nacional de Saúde Pública, Fundação Oswaldo Cruz, \\ Rio de Janeiro, RJ, Brasil
}

\author{
Correspondence \\ A.C.A.X. De-Oliveira \\ Laboratório de Toxicologia \\ Ambiental \\ Departamento de Ciências Biológicas \\ Escola Nacional de Saúde Pública \\ FIOCRUZ \\ Av. Brasil, 4036 \\ 21040-361 Rio de Janeiro, RJ \\ Brasil \\ Fax: +55-21-2270-4427 \\ E-mail: ana.oliveira@ensp.fiocruz.br \\ Research supported by $\mathrm{CNPq}$ and \\ FAPERJ. F.P. Conte (PIBIC) and \\ F.J.R. Paumgartten were recipients \\ of fellowships from $\mathrm{CNPq}$.
}

Received July 11, 2006 Accepted January 31, 2007

\begin{abstract}
The effects of schistosomiasis on microsomal enzymes were studied on post-infection day 90 when accumulated damage and fibrosis are most intense but granulomatous reaction around the eggs harbored in the liver is smaller than during the earlier phases. Swiss Webster (SW) and DBA/2 mice of either sex ( $\mathrm{N}=12$ per sex per group) were infected with 100 Schistosoma mansoni cercariae on postnatal day 10 and killed on post-infection day 90. Cytochrome P-450 (CYP) concentration and alkoxyresorufin- $O$-dealkylases (EROD, MROD, BROD, and PROD), p-nitrophenol-hydroxylase (PNPH), coumarin-7-hydroxylase (COH), and UDP-glucuronosyltransferase (UGT) activities were measured in hepatic microsomes. Age-matched mice of the same sex and strain were used as controls. In S. mansoni-infected mice, CYP1Aand $2 \mathrm{~B}$-mediated activities (control $=100 \%$ ) were reduced in SW (EROD: male (M) 36\%, female (F) 38\%; MROD: M 38\%, F 39\%; BROD: M 46\%, F 19\%; PROD: M 50\%, F 28\%) and DBA/2 mice (EROD: M 64\%, F 58\%; MROD: M 60\%; BROD: F 49\%; PROD: M $73 \%$ ) while PNPH (CYP2E1) was decreased in SW (M 31\%, F 38\%) but not in DBA/2 mice. COH did not differ between infected and control DBA/2 and UGT, a phase-2 enzyme, was not altered by infection. In conclusion, chronic S. mansoni infection reduced total CYP content and all CYP-mediated activities evaluated in SW mice, including those catalyzed by CYP2E1 (PNPH), CYP1A (EROD, MROD) and 2B (BROD, PROD). In DBA/2 mice, however, CYP2A5and 2E1-mediated activities remained unchanged while total CYP content and activities mediated by other CYP isoforms were depressed during chronic schistosomiasis.
\end{abstract}

It has been reported that activities and levels of expression of cytochrome P-450 (CYP) isoforms are altered by inflammatory stimuli and by a variety of infections including some helminthic infections. In rats and sheep, for instance, the liver fluke Fasciola
Key words

- Schistosoma mansoni

- Pharmacokinetics

- Cytochrome P-450

- Monooxygenases

- Granuloma

- Liver microsomes hepatica causes a marked depression of various CYP monooxygenases $(1,2)$. In contrast to the down-regulation of most CYP isoforms, CYP2A5 was induced in mice infected with $F$. hepatica (3). Similarly, Opisthorchis viverrini enhanced the expression 
of hepatic CYP2A5 in male hamsters (4) and the expression of CYP2A6, an isoform orthologous to rodent CYP2A5, in humans (5). As observed with other trematode infections, it has also been reported that liver monooxygenase activities are modulated by Schistosoma mansoni. During the early phase of murine schistosomiasis, when the liver is still largely devoid of granulomas, infection causes only minor changes in monooxygenase activities, the direction and magnitude of which depend on the mouse strain and sex. Increased activity of some hepatic monooxygenases has been detected in male BALB/c mice 33 days after infection with $S$. mansoni (6). However, a study on male and female Swiss Webster (SW) and DBA/2 mice detected no change in CYP-mediated activities on post-infection day 15 (PID15), and only strain- and gender-specific minor changes of monooxygenase activities on PID30 (7). At this early stage of infection, ManhãesRocha et al. (7) also noted that there was no alteration of coumarin 7-hydroxylase, a marker of CYP2A5 activity, in male and female DBA/2 mice infected with $S$. mansoni cercariae.

A marked decline of several CYP-mediated activities has been found at a more advanced stage of infection (i.e., 48-55 days after infection) $(6,8,9)$, when worms are sexually mature and the immune reaction to parasite eggs as well as the size of hepatic granulomas are maximal (10). There are almost no data on the activities of microsomal enzymes at even more advanced phases when accumulated damage and fibrosis are intense but the immune reaction to parasite eggs harbored in the liver is down-modulated.

In the present study, we evaluated the effects of $S$. mansoni infection on the activities of CYP2A5 and other microsomal enzymes on PID90, when granulomas around newly deposited eggs are smaller than those observed during earlier phases.

SW and DBA/2 mice of either sex from the Oswaldo Cruz Foundation breeding stock were used. The animals were housed in standard plastic cages covered with stainless steel lids and containing wood shavings as bedding. Room temperature $\left(23 \pm 2^{\circ} \mathrm{C}\right)$, air relative humidity (approximately $70 \%$ ) and light/ dark cycle (lights on from 8:00 am to 8:00 $\mathrm{pm}$ ) were controlled in the animal facilities. Tap water and a commercial diet for rats and mice (Nuvital CR1, Nuvilab ${ }^{\circledR}$, Curitiba, PR, Brazil) were provided ad libitum. The experiments were conducted in accordance with Brazilian animal protection and welfare laws and the research project was approved by the Ethics Committee on the Use of Animals, Oswaldo Cruz Foundation. Statistical comparisons within each mouse strain were made by the Kruskal-Wallis test followed by the Mann-Whitney U-test, with the level of significance set at $\mathrm{P}<0.05$.

$\mathrm{SW}$ and DBA/2 mice were infected with S. mansoni (BH strain) cercariae as described in detail elsewhere (11). Briefly, 10-day-old pups were transferred to Petri dishes $(5 \mathrm{~cm}$ in diameter, one pup per dish) containing $3 \mathrm{~mL}$ dechlorinated water with 100 cercariae. Pups were kept warm while infection took place by $60-\mathrm{W}$ tungsten lamps located close to the Petri dishes. Under these conditions, the pup's tail and paws as well as all the ventral part of their body were exposed to cercarial penetration for $20 \mathrm{~min}$. Immediately after being infected, the pups were returned to the cage of their mothers. A few drops of Lugol's iodine were then added to each dish and the number of cercariae that failed to penetrate the skin of the mice (i.e., separated cercarial heads and intact cercariae) was counted under a stereomicroscope. Skin penetration by the cercariae was very efficient (97 to $100 \%$ ) irrespective of mouse sex and strain. Control (sham-treated) mice were treated exactly as infected animals except that no cercaria was added to the Petri dish water. Infected mice and their age-matched controls were killed by cervical dislocation on PID90, i.e., on postnatal day 100. Livers were removed as quickly as possible, freed from fat and extra 
tissue, weighed and frozen in liquid nitrogen until further use. Hepatic microsomes (pools of two organs) were prepared as described by Manhães-Rocha et al. (7). Microsomal protein concentration was determined by the method of Bradford and total CYP content and the activities of pentoxy- (PROD), benzyloxy- (BROD), methoxy- (MROD), and ethoxy- (EROD) resorufin- $O$-dealkylases, coumarin 7-hydroxylase $(\mathrm{COH})$, and UDPglucuronosyltransferase (UGT) were determined as reported elsewhere (7). Nitrophenol-hydroxylase activity in the mouse liver microsomal fraction was determined by the real-time kinetic method described in detail by Allis and Robinson (12). Serum alanine aminotransferase (ALT) was assayed by a colorimetric method using a commercially available kit (Bioclin ${ }^{\circledR}$, Belo Horizonte, MG, Brazil) and a microplate spectrophotometer reader (Spectramax Plus ${ }^{\circledR}$, Molecular Devices Co., Sunnyvale, CA, USA). Blood was taken from the periorbital venous sinus at the time of sacrifice on PID90. ALT activity was reported as international units per liter (IU/L).

As shown in Table 1, infection with $S$. mansoni (PID90) markedly depressed total CYP content in the liver of SW and DBA/2 mice irrespective of sex. Monooxygenase activities catalyzed by CYP1A (MROD and EROD) and 2B (BROD and PROD) subfamily isoforms were decreased by chronic infection in both strains and genders (M: male, F: female) but, in these cases, reductions (control: 100\%) were more pronounced among SW mice (EROD: M 36\%, F 38\%; MROD: M 38\%, F 39\%; BROD: M 46\%, F 19\%; PROD: M 50\%, F 28\%) than among DBA/2 mice (EROD: M 64\%, F 58\%; MROD: M 60\%; BROD: F, 49\%; PROD: M $73 \%$ ) (Table 1). In non-infected SW and DBA/2 mice, PROD and BROD activities were higher in females than in males, a finding consistent with the higher expression of CYP2B9/10 in females. This sexrelated difference regarding CYP2B activity was not apparent in infected SW mice (Table 1). CYP2E1-mediated activity (nitrophenolhydroxylase) was also depressed among infected SW mice of either sex (M 31\%, F $38 \%$ ) but it remained unchanged among infected male and female DBA/2 mice (Table 1). These results indicate that CYP-mediated activities were depressed in chronically infected mice on PID90 and that the effects of $S$. mansoni infection were more intense on SW than on DBA/2 mice. The differences between the two strains could be explained at least in part by differences in the number of parasite eggs harbored in the liver parenchyma. As demonstrated by Fidalgo-Neto et al. (11) in mice infected with 100 cercariae on postnatal day 10, although skin penetration by cercariae was very effective and did not differ between the SW and DBA/2 strains, the proportion of penetrating cercariae that further developed into adult worms - and thus the number of eggs trapped in the host's liver on PID90 - was higher in the former strain.

The levels of CYP2A5 expression vary among mouse strains, some of which either do not express a functional CYP2A5 or express it at very low levels. Since $\mathrm{COH}$, a CYP2A5-mediated activity, is rather low in $\mathrm{SW}$, the effects of infection on CYP2A5 were determined only in DBA/2 mice. As expected, $\mathrm{COH}$ activity was higher in females than in males. S. mansoni infection, however, did not alter $\mathrm{COH}$ in males or in females (Table 1).

The effects of chronic schistosomiasis on the activity of UGT, a phase II microsomal enzyme, were also evaluated. As shown in Table 1, UGT activity was somewhat higher in non-infected male SW mice than in females, a difference between genders that was not apparent in the DBA/2 strain. $S$. mansoni infection, on the other hand, did not cause any change in UGT activity in SW or $\mathrm{DBA} / 2$ mice.

The mechanisms by which $S$. mansoni and some other parasitic infections modify 
the expression and activity of various CYP isoforms are still far from being entirely understood. The down-regulation of liver CYPs during murine schistosomiasis seems to depend on the development of a granuloma around the parasite's eggs since no changes in enzyme activities were observed in athymic nude mice (13) or in cases of unisexual S. mansoni infection (14). This view of the importance of circumoval granulomas for the down-modulation of CYPs is additionally supported by the fact that liver microsomal enzyme activities remain unchanged on PID15, when worms are not yet sexually mature, and only minor changes are found on PID30, when very few eggs, if any, are found in the hepatic tissue $(7,11)$. It remains unclear, however, how pathophysiological changes associated with schistoso- mal granulomas alter the expression and activity of CYP enzymes. Based mainly on studies using bacterial lipopolysaccharide as well as other immunostimulants, it has been proposed that an increase in the levels of nitric oxide (NO) due to the induction of nitric oxide synthase (NOS2 or iNOS) is a major factor mediating the suppression of CYP expression and activity by infections and pro-inflammatory stimuli (15). Morgan (16), however, has failed to demonstrate that overproduction of NO is an essential link between lipopolysaccharide treatment and suppression of CYPs. Whether NO and a variety of cytokines produced in the vicinity of schistosomal granulomas play a role in the down-modulation of CYP isoforms by the infection remains to be further elucidated.

\begin{tabular}{|c|c|c|c|c|c|c|c|c|}
\hline & \multicolumn{4}{|c|}{ Swiss Webster mice } & \multicolumn{4}{|c|}{$\mathrm{DBA} / 2$ mice } \\
\hline & \multicolumn{2}{|c|}{ Infected } & \multicolumn{2}{|c|}{ Control } & \multicolumn{2}{|c|}{ Infected } & \multicolumn{2}{|c|}{ Control } \\
\hline & Males & Females & Males & Females & Males & Females & Males & Females \\
\hline $\begin{array}{l}\text { Total CYP } \\
\text { (pmol CYP/mg ptn) }\end{array}$ & $\begin{array}{c}443.3 \pm 37.6^{*} \\
(63 \%)\end{array}$ & $\begin{array}{c}428.8 \pm 68.9^{*} \\
(64 \%)\end{array}$ & $707.8 \pm 27.1$ & $668.4 \pm 58.4$ & $\begin{array}{c}350.8 \pm 30.2^{*} \\
(60 \%)\end{array}$ & $\begin{array}{c}365.4 \pm 16.4^{*} \\
(60 \%)\end{array}$ & $579.8 \pm 98.1$ & $609.1 \pm 24.6$ \\
\hline \multicolumn{9}{|c|}{ X-ROD (pmol resorufin $\mathrm{mg} \mathrm{ptn}^{-1} \mathrm{~min}^{-1}$ ) } \\
\hline EROD & $\begin{array}{c}35.4 \pm 20.8^{*} \\
(36 \%)\end{array}$ & $\begin{array}{l}27.3 \pm 12.3^{*} \\
(38 \%)\end{array}$ & $99.2 \pm 20.0$ & $72.4 \pm 14.9$ & $\begin{array}{c}77.6 \pm 25.6^{*} \\
(64 \%)\end{array}$ & $\begin{array}{l}50.5 \pm 12.6^{\star} \\
(58 \%)\end{array}$ & $121.2 \pm 20.3$ & $87.2 \pm 15.5$ \\
\hline MROD & $\begin{array}{c}69.8 \pm 33.0^{*} \\
(38 \%)\end{array}$ & $\begin{array}{c}43.6 \pm 20.1^{*} \\
(39 \%)\end{array}$ & $183.7 \pm 38.0$ & $112.1 \pm 24.7$ & $\begin{array}{c}133.2 \pm 20.8^{*} \\
(60 \%)\end{array}$ & $90.8 \pm 27.5$ & $222.4 \pm 32.0$ & $122.0 \pm 24.6$ \\
\hline BROD & $\begin{array}{c}13.8 \pm 4.6^{*} \\
(46 \%)\end{array}$ & $\begin{array}{c}15.0 \pm 6.7^{*} \\
(19 \%)\end{array}$ & $29.9 \pm 8.6^{+}$ & $79.3 \pm 19.4$ & $22.2 \pm 2.2^{+}$ & $\begin{array}{c}38.6 \pm 9.6^{*} \\
(49 \%)\end{array}$ & $33.4 \pm 11.6^{+}$ & $78.6 \pm 21.9$ \\
\hline PROD & $\begin{array}{l}4.9 \pm 2.0^{*} \\
(50 \%)\end{array}$ & $\begin{array}{c}4.9 \pm 1.7^{*} \\
(28 \%)\end{array}$ & $9.7 \pm 2.1^{+}$ & $17.6 \pm 1.9$ & $\begin{array}{l}6.8 \pm 0.8^{*+} \\
(73 \%)\end{array}$ & $12.0 \pm 2.8$ & $9.3 \pm 1.0^{+}$ & $13.4 \pm 1.3$ \\
\hline $\begin{array}{l}\text { PNPH (nmol 4-nitrocathecol } \\
\left.\mathrm{mg} \mathrm{ptn}^{-1} \mathrm{~min}^{-1}\right)\end{array}$ & $\begin{array}{l}1.0 \pm 0.2^{*} \\
(31 \%)\end{array}$ & $\begin{array}{l}0.9 \pm 0.2^{*} \\
(38 \%)\end{array}$ & $3.2 \pm 0.7$ & $2.4 \pm 0.4$ & $2.2 \pm 0.3$ & $2.5 \pm 0.4$ & $2.5 \pm 0.3$ & $2.7 \pm 0.3$ \\
\hline $\begin{array}{l}\mathrm{COH} \text { (pmol umbelliferone } \\
\mathrm{mg} \mathrm{ptn}^{-1} \mathrm{~min}^{-1} \text { ) }\end{array}$ & - & - & - & - & $70.5 \pm 27.8^{+}$ & $232.4 \pm 51.8$ & $55.3 \pm 22.8^{+}$ & $202.9 \pm 74.7$ \\
\hline $\begin{array}{l}\text { UGT (nmol p-nitrophenol } \\
\text { conjugate } \mathrm{mg} \mathrm{ptn}^{-1} \mathrm{~min}^{-1} \text { ) }\end{array}$ & $8.4 \pm 0.5$ & $11.1 \pm 2.4$ & $10.9 \pm 1.5^{+}$ & $7.6 \pm 1.0$ & $14.6 \pm 1.3$ & $16.1 \pm 2.0$ & $13.7 \pm 4.2$ & $14.4 \pm 1.6$ \\
\hline ALT (blood serum, IU/L) & - & - & - & - & $50.5 \pm 12.3$ & $51.7 \pm 23.1$ & $47.2 \pm 7.7$ & $48.2 \pm 12.6$ \\
\hline
\end{tabular}

Data are reported as means \pm SD. Microsomes were obtained from pools of two livers. $N=12$ mice (6 microsomes) per group. Alanine aminotransferase (ALT) was measured in serum samples from 6 mice. Coumarin-7-hydroxylase $(\mathrm{COH})$ (hepatic microsomes) and ALT (blood serum) were determined only in DBA/2 mice. ptn $=$ protein.

${ }^{*} \mathrm{P}<0.05$ compared to the non-infected control of the same gender and strain (Mann-Whitney U-test). A superscript plus (+) indicates that males differ from females of the strain; the percentages for the treatment group in relation to the respective control mean values $(=100 \%)$ are shown in parentheses whenever values for infected mice differed from those for controls. 
The mechanism by which CYP2A5 is modulated by infections apparently differs from that of most CYP isoforms. In rodent models, expression of CYP2A5 was induced by trematode infections such as those caused by $F$. hepatica and $O$. viverrini $(3,4,17)$, as well as by malaria (18) and by bacterial (Helicobacter hepaticus) and viral (HBV) hepatitis. It is noteworthy that CYP2A5 was specifically induced in these infection models, whereas total-CYP content was decreased and CYP isoforms other than CYP2A5 were either depressed or unaffected. Recently, Gilmore et al. (17) suggested that the induction of CYP2A5 may be mediated by direct cellular damage rather than by an indirect pathway involving pro-inflammatory cytokines. This hypothesis seems to be supported by the fact that CYP2A5 is overexpressed in infections that cause a rather extensive damage to liver cells, such as fascioliasis, opisthorchiasis, and hepatitis. Gilmore et al. (17) also reported that induction of CYP2A5 by pyrazole is associated with a chemically produced hepatocellular injury. Recently, DeOliveira et al. (18) showed that the induction of CYP2A5 by Plasmodium berghei (ANKA) infection was also associated with an increase of ALT and aspartate aminotransferase (AST) levels in blood serum. In the present study, blood serum ALT activity did not differ between infected and non-infected DBA/2 mice on PID90 (Table 1), indicating that $S$. mansoni infection did not produce a biochemically detectable liver injury. As pointed out by Brunet et al. (19), while granulomas themselves are clearly pathogenic, they also sequester molecules released by parasite eggs and in so doing they protect the hepatocytes from toxic miracidial secretions that otherwise could lead to cell injury and liver failure. F. hepatica, on the other hand, causes extensive liver cell destruction, thereby producing marked elevations of plasma ALT and AST levels, as the juvenile flukes migrate through the organ (20). The induction of CYP2A5 by fascioliasis but not by $S$. mansoni infection is thus consistent with the view that up-regulation of this isoenzyme depends on the intensity of cellular damage and that there is a threshold for this effect (17).

The results of the present study show that, during chronic schistosomiasis (PID90), except for CYP2E1 that remained unchanged in the DBA/2 strain, total CYP levels and the activities mediated by CYP1A1/2, 2B and $2 \mathrm{E} 1$ are depressed in the liver of SW and DBA/2 mice. S. mansoni infection, on the other hand, did not cause any change in CYP2A5 or UGT, a phase 2 microsomal enzyme. These results indicate that decline of liver CYP activities caused by S. mansoni is still present when infection evolves to a phase characterized by fibrosis, accumulated damage and a less intense host immune response to the parasite egg antigens.

\section{Acknowledgments}

The authors are grateful to the staff of the Department of Malacology of the Oswaldo Cruz Institute for the generous supply of Schistosoma mansoni cercariae throughout the study.

\section{References}

1. Galtier P, Battaglia A, More J, Franc M. Impairment of drug metabolism by the liver in experimental fascioliasis in the rat. $J$ Pharm Pharmacol 1983; 35: 729-733.

2. Calleja C, Bigot K, Eeckhoutte C, Sibille P, Boulard C, Galtier P. Comparison of hepatic and renal drug-metabolising enzyme activities in sheep given single or two-fold challenge infections with Fasciola hepatica. Int J Parasitol 2000; 30: 953-958.
3. Montero R, Gentile GJ, Frederick L, McMannis J, Murphy T, Silva G, et al. Induced expression of CYP2A5 in inflamed trematode-infested mouse liver. Mutagenesis 1999; 14: 217-220.

4. Kirby GM, Pelkonen P, Vatanasapt V, Camus AM, Wild CP, Lang MA. Association of liver fluke (Opisthorchis viverrini) infestation with increased expression of cytochrome P450 and carcinogen metabolism in male hamster liver. Mol Carcinog 1994; 11: 81-89. 
5. Satarug S, Lang MA, Yongvanit $P$, Sithithaworn $P$, Mairiang $E$, Mairiang $P$, et al. Induction of cytochrome P450 2A6 expression in humans by the carcinogenic parasite infection, Opisthorchiasis viverrini. Cancer Epidemiol Biomarkers Prev 1996; 5: 795-800.

6. Sheweita SA, Mangoura SA, el-Shemi AG. Different levels of Schistosoma mansoni infection induce changes in drug-metabolizing enzymes. J Helminthol 1998; 72: 71-77.

7. Manhaes-Rocha DA, Conte FP, Fidalgo-Neto AA, De-Oliveira AC, Ribeiro-Pinto LF, Paumgartten FJ. Alterations of hepatic microsomal enzymes in the early phase of murine schistosomiasis. Acta Trop 2005; 95: 58-66.

8. Cha YN, Edwards R. Effect of Schistosoma mansoni infection on the hepatic drug-metabolizing capacity of mice. J Pharmacol Exp Ther 1976; 199: 432-440.

9. Sheweita SA, Mubark J, Doenhofe MJ, Mostafa MH, Margison GP, O'Connor PJ, et al. Changes in the expression of cytochrome P450 isozymes and related carcinogen metabolizing enzyme activities in Schistosoma mansoni-infected mice. J Helminthol 2002; 76: 71-78.

10. Cheever AW, Lenzi JA, Lenzi HL, Andrade ZA. Experimental models of Schistosoma mansoni infection. Mem Inst Oswaldo Cruz 2002; 97: 917-940.

11. Fidalgo-Neto AA, De-Carvalho RR, De-Oliveira ACAX, ManhãesRocha DA, Paumgartten FJR. Penetration and maturation of Schistosoma mansoni in suckling and adult Swiss Webster and DBA/2 mice. J Exp Anim Sci 2004; 43: 29-38.

12. Allis JW, Robinson BL. A kinetic assay for p-nitrophenol hydroxy- lase in rat liver microsomes. Anal Biochem 1994; 219: 49-52.

13. Cha YN, Byram JE, Heine HS, Bueding E. Effect of Schistosoma mansoni infection on hepatic drug-metabolizing capacity of athymic nude mice. Am J Trop Med Hyg 1980; 29: 234-238.

14. Cha YN, Heine HS, Bueding E. Effect of unisexual Schistosoma mansoni infections on hepatic drug metabolism of mice. Am J Trop Med Hyg 1980; 29: 227-233.

15. Khatsenko OG, Gross SS, Rifkind AB, Vane JR. Nitric oxide is a mediator of the decrease in cytochrome P450-dependent metabolism caused by immunostimulants. Proc Natl Acad Sci U S A 1993; 90: 11147-11151.

16. Morgan ET. Regulation of cytochrome p450 by inflammatory mediators: why and how? Drug Metab Dispos 2001; 29: 207-212.

17. Gilmore WJ, Hartmann G, Piquette-Miller M, Marriott J, Kirby GM. Effects of lipopolysaccharide-stimulated inflammation and pyrazolemediated hepatocellular injury on mouse hepatic Cyp2a5 expression. Toxicology 2003; 184: 211-226.

18. De-Oliveira AC, Da-Matta AC, Paumgartten FJ. Plasmodium berghei (ANKA): infection induces CYP2A5 and 2E1 while depressing other CYP isoforms in the mouse liver. Exp Parasitol 2006; 113: 256-261.

19. Brunet LR, Dunne DW, Pearce EJ. Cytokine interaction and immune responses during Schistosoma mansoni infection. Parasitol Today 1998; 14: 422-427.

20. Kolodziejczyk L, Siemieniuk E, Skrzydlewska E. Antioxidant potential of rat liver in experimental infection with Fasciola hepatica. Parasitol Res 2005; 96: 367-372. 